\title{
Metabolic Damage: Do Negative Metabolic Adaptations During Underfeeding Persist After Refeeding in Non-Obese Populations?
}

\section{Authors:}

Anastasia Zinchenko ${ }^{1 *}$

Menno Henselmans ${ }^{1}$

1. Bayesian Bodybuilding R\&D

Department, Bayesian

Bodybuilding, Lingsesdijk 46B,

4207 AE Gorinchem,

The Netherlands.

\section{* Correspondence:}

E-mails:

a.zinchenko@live.de

MennoHenselmans@Bayesian

Bodybuilding.com

Key words: metabolic damage, metabolic slowing, weight regain, weight loss, weight cycling

\section{Abstract}

Several researches have proposed that a prolonged period of caloric restriction (CR) may have a permanent, adverse effect on basal metabolism, fostering the development of obesity. This reported metabolic slowing has been associated with a reduction in resting metabolic rate (RMR) beyond what is predicted by the change in body composition, promoting the idea that metabolism can be permanently damaged. This systematic review investigates if prolonged CR exhibits a permanent, negative effect on basal metabolism.

This paper reviews literature reporting weight loss and weight regain of individuals who were initially within a healthy weight range, such as the long-term Minnesota starvation experiment, in addition to research on chronically undernourished individuals, such as patients with anorexia nervosa, before and after recovery. Quantification of basal metabolism before and after prolonged CR revealed that body composition is the most critical factor in determining absolute RMR in neutral energy balance. Changes in energy balance induce a rapid yet reversible increase or decrease in RMR. Previous reports may have come to erroneous conclusions in favor of the metabolic damage hypothesis because they did not examine the full recovery period in the Minnesota experiment or neglected the influence of energy balance on RMR. Our findings indicate that the theory of permanent, diet-induced metabolic slowing in non-obese individuals is not supported by the current literature. 


\section{Introduction}

Previous research has suggested that a prolonged period of caloric restriction (CR) leads to a permanent decrease in resting metabolic rate (RMR) that goes beyond the value expected from the present body composition [1-4]. Metabolic slowing, originating from adaptive thermogenesis (AT) in a calorierestricted state, was hypothesized to be irreversible upon the return to neutral energy balance [1] and lead to 'metabolic damage'. Metabolic damage refers to a weight loss induced decrease in RMR that is beyond the value expected from the present body composition and persists after weight regain.

It was suggested that metabolic damage is responsible for post-diet weight regain of overweight and obese individuals if weight-reduced individuals do not maintain a high level of physical activity or a calorie restricted state [1]. A recent study examining RMR of participants of "The Biggest Loser" challenge, who lost on average $58 \mathrm{~kg}$ in
30 weeks and regained approximately 41 $\mathrm{kg}$ in the following 6 years, found that the participants had a significantly lower RMR relative to their pre-dieting level even after nearly reverting to their initial body composition [4].

Reports reanalyzing the data from the Minnesota experiment [5] suggested that permanent metabolic slowing also occurs in lean individuals. In this study, 32 healthy young men underwent severe caloric restriction for 24 weeks with a targeted weight loss of approximately $1 \mathrm{~kg}$ per week. The weight regain phase consisted of two phases: a 12-week controlled rehabilitation period and an 8week ad libitum period, in which the subjects did not follow a prescribed diet; however, their food intake was still recorded. After reanalyzing the data from this experiment, Dulloo and coworkers observed a disproportionate rate of fat recovery relative to fat-free mass (FFM) recovery and proposed that it is the reason for favorable fat gain after CR [6-8]. Furthermore, the same researchers 
suggested that weight loss diets make "the lean fatter," because CR-induced feedback signals suppress RMR normalization until the initial fat mass $(\mathrm{FM})$ is fully recovered ("fat-stores memory") $[8,7]$. The post-diet shift towards an unfavorable body composition may result in repeated dieting attempts and increase the risk of becoming overweight [8]. Indeed, repeated weight cycling has been associated with weight gain over time [9] and is speculated to increase the risk of all-cause and cardiovascular mortality [10].

Considering that the majority of the population in Western countries is dissatisfied with their appearance [11] and about one half of individuals who are within the reference weight range reported undergoing weight loss interventions in order to lose weight [12], a permanent $\mathrm{RMR}$ reduction after dieting may present a health hazard to the general population. For this reason, this paper investigates whether diet-induced metabolic slowing is responsible for the difficulty in maintaining reduced body weight.
Particular attention was devoted to research on RMR related to the present body composition of subjects who previously underwent a prolonged period of CR but were no longer in an energyrestricted state. This context aimed to control for body composition and eliminate transient effects of CR, such as the $\mathrm{CR}$ induced reduction in spontaneous physical activity [13], that influence energy expenditure. If a sustained suppression of RMR occurs after weight loss dieting, then a return to the initial body composition should result in a lower RMR relative to the baseline and compared to weight-matched control subjects without a history of weight cycling ('metabolic damage').

\section{Methods}

\subsection{Used terms}

In this review, the terms resting metabolic rate (RMR), resting energy expenditure (REE), basal metabolic rate (BMR), basal energy expenditure (BEE), sleeping metabolic rate (SMR) and sleeping energy expenditure (SEE) are 
used interchangeably to report previous findings that differed in terminology but used a comparable experimental measurement methodology, specifically indirect calorimetry after an overnight fast.

\subsection{Literature search}

An electronic literature search was conducted in the PubMed database using the keywords caloric restriction, caloric deficit, weight loss, diet, starvation, underfeeding, malnourished, anorexia, anorectic, weight regain, weight gain, refeed, overfeeding, weight change, weight maintenance, basal metabolic rate, basal metabolism, metabolic rate, metabolism, energy expenditure, BMR, BEE, RMR, REE, SMR and SEE in any combination using the Boolean operators AND and OR. Titles and abstracts of human studies published until December 2015 were assessed for their relevance for this review.

Articles were selected when they contained the information required to determine changes of FM, FFM and RMR following weight loss and subsequent weight regain or weight regain relative to the weight-reduced state for malnourished subjects.

Bibliographies of relevant original research articles and reviews were screened for additional relevant references.

\subsection{Data analysis}

To test the metabolic slowing hypothesis, three equations were used that were previously used to calculate RMR in the literature [14-16]. The fat mass percentage (FM\%) based equations developed by Bosy-Westphal and coworkers [14], with each equation specific to a particular FM\% range, are particularly suitable for the RMR prediction of individuals who experienced significant weight loss with a subsequent weight regain. These equations were shown to give a comparable precision to accurate organ mass based RMR predictions, unlike many other formulas that only incorporate weight or only lean body mass and fat mass [17]. Potential 
error in the prediction of absolute RMR due to individual variability [18] or inaccuracies resulting from differences in body composition measurements (e.g. DEXA vs. BIA) [17] can be eliminated by using predicted RMR as a normalization factor [17]. If the measured RMR differs from the predicted value, then the difference between the predicted and measured value should stay constant throughout the study. Thus, the $R M R_{m / p^{-}}$ ratio of measured to predicted RMR - as used previously [16] - was used to relate the metabolic state of subject groups before and after weight loss across a number of studies.

$$
R M R_{m / p}-\text { ratio }=\frac{R M R_{\text {measured }}}{R M R_{\text {predicted }}}
$$

A constant $\mathrm{RMR}_{\mathrm{m} / \mathrm{p}}$-ratio throughout the weight change intervention suggests that the metabolic rate changes in proportion to the changing body composition. A decrease in $\mathrm{RMR}_{\mathrm{m} / \mathrm{p}}$-ratio indicates a decreased basal metabolism beyond what is expected based on the body composition change; an increase indicates an increase in metabolic rate beyond what is expected based on the body composition change.

For the conversion of energy units, the relationship $1 \mathrm{kcal}=4.184 \mathrm{~kJ}$ was used. RMR values for Minnesota experiment subjects were calculated using the factor $20.5 \mathrm{~kJ} / \mathrm{L}$ oxygen [6].

\subsection{Statistical analysis}

Statistical analysis was conducted using IBM SPSS Statistics 20.0.0 with additional manual calculations in Excel from Microsoft Office Professional Plus 2013. Data are presented as means $(M)$ plus standard deviations (SD) unless otherwise specified. 


\section{Results}

\subsection{Metabolic damage during} weight loss and regain interventions in normal weight individuals

To examine the relationship between RMR and body composition over time, we calculated the $\mathrm{RMR}_{\mathrm{m} / \mathrm{p}}$-ratio for the subjects of the Minnesota experiment (Table 1). The data calculated with all three equations [14-16] was consistent in showing that the $\mathrm{RMR}_{\mathrm{m} / \mathrm{p}}$-ratio decreased over the semi-starvation period compared to baseline and subsequently increased in correspondence with body weight regain over the controlled 12-week reefed period. Two months after the subjects transitioned to the ad libitum diet, the $\mathrm{RMR}_{\mathrm{m} / \mathrm{p}}$-ratio calculated with the equations reported by Bosy-Westphal and coworkers [14] returned exactly to the baseline value without a significant difference between baseline and the end of the recovery period $(p=.98)$. The use of the equation adapted from Doucet and coworkers [15] showed a trend towards a higher postdieting $\mathrm{RMR}_{\mathrm{m} / \mathrm{p}}$-ratio $(t(10)=2.09$, $p=.06)$. The calculations based on the third equation [16] gave a significantly higher $\mathrm{RMR}_{\mathrm{m} / \mathrm{p}}$-ratio after semi-starvation and subsequent weight regain compared to baseline $(t(10)=2.61, p=.03)$. Collectively, these data suggest that the subjects maintained their relative metabolic rate or even experienced an increase in their body composition adjusted basal metabolism compared to baseline. In fact, despite incomplete FFM recovery after 20 weeks of rehabilitation $(t(10)=2.7, p=.02)$, the subjects' measured RMR was significantly higher than at baseline $(t(10)=2.42, p=.04)$. 
Medical Research Archives, Vol. 4, Issue 8, December 2016

Metabolic Damage: Do Negative Metabolic Adaptations During Underfeeding

Persist After Refeeding in Non-Obese Populations?

Table 1. Changes in body composition and metabolic parameters over the course of the Minnesota experiment

\begin{tabular}{|c|c|c|c|c|c|c|}
\hline & \multicolumn{2}{|c|}{ Body weight (kg) } & \multicolumn{2}{|c|}{$\begin{array}{r}\text { FFM } \\
(\mathrm{kg})\end{array}$} & \multicolumn{2}{|c|}{$\begin{array}{c}\text { RMR (MJ) } \\
\text { (RMR (kcal)) }\end{array}$} \\
\hline & $M$ & $S D$ & $M$ & $S D$ & $M$ & $S D$ \\
\hline Baseline, $\mathrm{n}=32$ & 69.4 & 5.8 & 59.5 & 4.2 & $\begin{array}{c}6.70 \\
(1601)\end{array}$ & $\begin{array}{l}0.40 \\
(95)\end{array}$ \\
\hline $\mathrm{S}-24 \mathrm{wk}, \mathrm{n}=32$ & 52.3 & 4 & 49.5 & 3.5 & $\begin{array}{r}4.09 \\
(977)\end{array}$ & $\begin{array}{l}0.41 \\
(98)\end{array}$ \\
\hline $\mathrm{R}-12 \mathrm{wk}, \mathrm{n}=32$ & 59.1 & 3.9 & 52.7 & 3.7 & $\begin{array}{c}5.38 \\
(1285)\end{array}$ & $\begin{array}{r}0.46 \\
(111)\end{array}$ \\
\hline \multicolumn{7}{|c|}{ Recovery $\%$} \\
\hline $836 \mathrm{MJ}$ & 30 & 27 & 34 & 33 & 29 & 16 \\
\hline $947 \mathrm{MJ}$ & 30 & 8 & 21 & 10 & 47 & 13 \\
\hline $1097 \mathrm{MJ}$ & 42 & 17 & 36 & 11 & 56 & 17 \\
\hline $1192 \mathrm{MJ}$ & 59 & 16 & 32 & 15 & 65 & 10 \\
\hline $\mathrm{R}-20 \mathrm{wk}, \mathrm{n}-20$ & 70.5 & 4.5 & 57 & 3.4 & $\begin{array}{c}7.06 \\
(1688)\end{array}$ & $\begin{array}{r}0.50 \\
(119)\end{array}$ \\
\hline Baseline $^{20}$ & 67 & 5 & 58.3 & 3.4 & $\begin{array}{c}6.68 \\
(1596)\end{array}$ & $\begin{array}{l}0.35 \\
(83)\end{array}$ \\
\hline
\end{tabular}

$\mathrm{RMR}_{\mathrm{m} / \mathrm{p}}$

\begin{tabular}{ccccccc}
\hline $\begin{array}{l}\text { Calculated with equation } \\
\text { based on }\end{array}$ & $\begin{array}{c}\text { Bosy-Westphal et } \\
\text { al. }[14]\end{array}$ & \multicolumn{2}{c}{$\begin{array}{c}\text { Camps } \text { et al. } \\
{[16]}\end{array}$} & \multicolumn{2}{c}{$\begin{array}{c}\text { Doucet et al. } \\
{[15]}\end{array}$} \\
\hline & $M$ & $S D$ & $M$ & $S D$ & $M$ & $S D$ \\
\hline Baseline, $\mathrm{n}=32$ & 1.09 & 0.07 & 0.94 & 0.05 & 1.01 & 0.05 \\
$\mathrm{~S}-24 \mathrm{wk}, \mathrm{n}=32$ & 0.83 & 0.08 & 0.69 & 0.07 & 0.73 & 0.07 \\
$\mathrm{R}-12 \mathrm{wk}, \mathrm{n}=32$ & 0.98 & 0.07 & 0.85 & 0.08 & 0.90 & 0.08 \\
& & & & & & \\
$\mathrm{R}-20 \mathrm{wk}, \mathrm{n}-20$ & 1.13 & 0.05 & 1.08 & 0.05 & 1.01 & 0.05 \\
Baseline & 1.13 & 0.07 & 1.03 & 0.05 & 0.95 & 0.05 \\
\hline
\end{tabular}

$M$ - mean; $S D$ - standard deviation; S - 24 end of the semi-starvation period of 24 weeks; R -12 after 12 weeks controlled refeed;

R -20 after 20 weeks recovery (12 weeks controlled and 8 weeks ad libitum diet), $\mathrm{n}=$ subject number, recovery $\%$ - percentage of the regained weight during controlled refeed relative to the weight lost in semi-starvation period (recovery $\%=100 *[\mathrm{R} 12$ $\mathrm{S} 24] /\left[\right.$ baseline - S24]), Baseline ${ }^{20}$ - baseline data for the 20 subjects examined at the time point $\mathrm{R}-20$ 
The rate of body fat gain and RMR recovery in the controlled rehabilitation period was influenced by energy intake (Table 1). The subjects were divided into 4 groups that received diets differing in caloric content. Initially, in the experimental design, it was planned that the groups' energy intakes increased in 1.6 MJ (400 kcal) increments, from the lowest energy group consuming $400 \mathrm{kcal}$ more than each subject's estimated energy maintenance requirements at the end of starvation to a group consuming a diet with an energy content of 6.7 MJ (1600 kcal) above energy maintenance requirements. However, the subsequent analysis of the diets showed that the groups received supplements of a lower calorific value than planned and the two lowest calorie groups recovered only to a small degree in the first 6 weeks. For this reason, the energy intake was increased in the second half of the controlled rehabilitation period. In the entire 12week rehabilitation phase, not only body weight, but also the $\mathrm{RMR}_{\mathrm{m} / \mathrm{p}}$-ratio, which inherently controls for body composition, increased in relation to energy intake
(Figure 1). The group with the highest energy intake had a significantly higher $\mathrm{RMR}_{\mathrm{m} / \mathrm{p}}$-ratio compared to the group with the lowest energy intake $(t(14)=3.23, p=$ .006). The $\mathrm{RMR}_{\mathrm{m} / \mathrm{p}}$-ratio correlated strongly and significantly with total energy intake in the refeeding period using the equation based on Doucet et al. [15] $(r=.97, p=.034)$. For the other two equations $[14,16]$, a clear trend was observed for the association between energy intake and the $\mathrm{RMR}_{\mathrm{m} / \mathrm{p}}$-ratio $(r=.95, p=.054 ; \quad r=.94, p=.06 ;$ respectively).

Previous computational modeling of energy metabolism during semi-starvation and refeeding also indicated that RMR is higher in positive energy balance compared to a calorie-restricted state despite identical body composition [19]. The RMR in week 12 of the semistarvation phase was significantly lower than the measured RMR in recovery week 12 despite identical FFM. The validity of this finding remained after controlling for body composition and including FM in the model. Analysis based on all of our equations [14-16] showed that the 
$\mathrm{RMR}_{\mathrm{m} / \mathrm{p}}$-ratio during semi-starvation was significantly lower than after 12 weeks of controlled refeeding (Table 2). Moreover, in the lowest energy group, the $\mathrm{RMR}_{\mathrm{m} / \mathrm{p}^{-}}$ ratio in the recovery period was significantly higher than during semi- starvation even though the subjects had significantly lower average FFM and identical FM. Collectively, these findings suggest that energy intake has an acute effect on RMR.

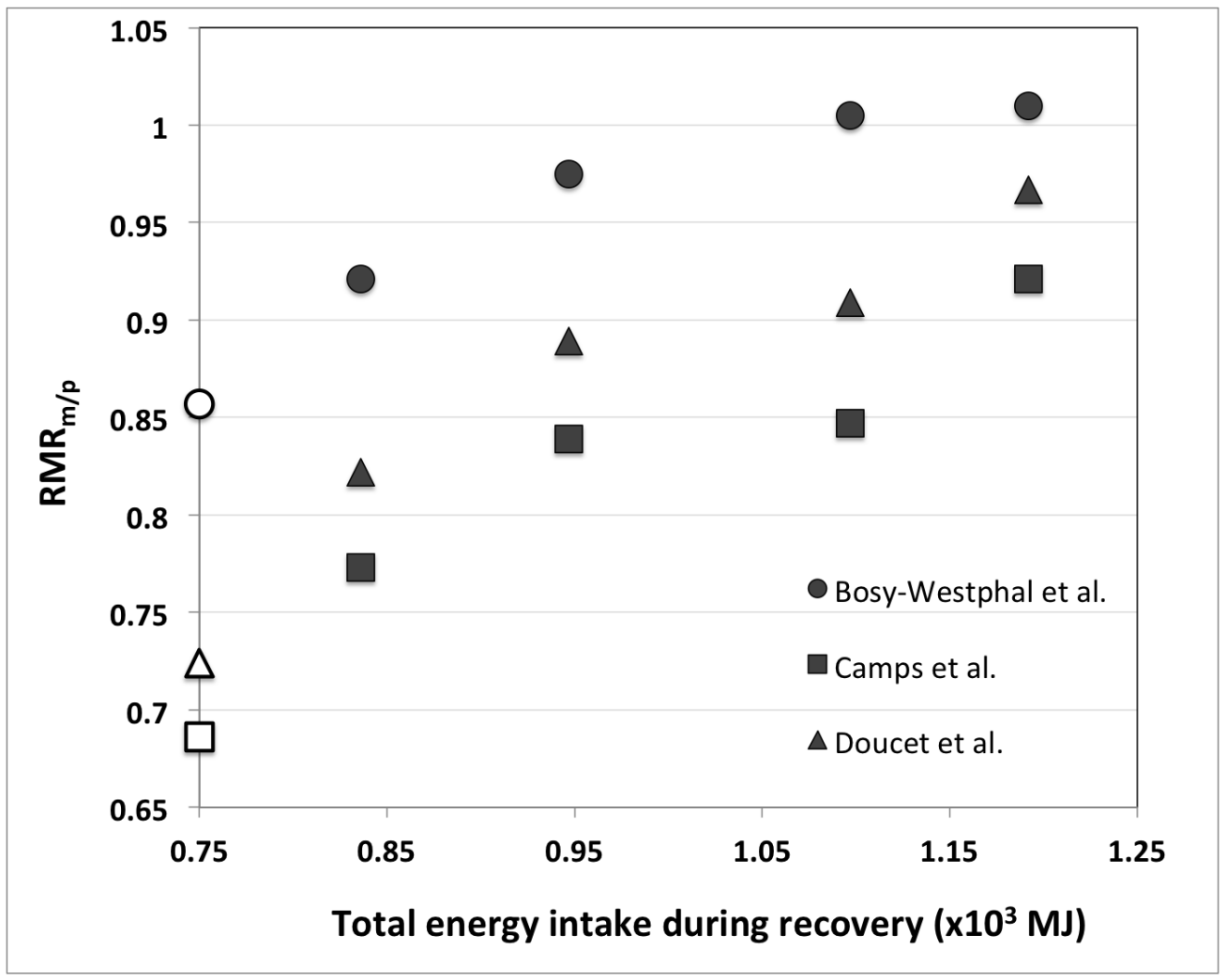

Figure 1. Changes in the $\mathrm{RMR}_{\mathrm{m} / \mathrm{p}}$-ratio related to energy intake. Different energy intake levels during the 12 week recovery period (gray) led to different recovery rates of the $\mathrm{RMR}_{\mathrm{m} / \mathrm{p}}$-ratio. Despite an identical starting point after semi-starvation (white) and controlling for body composition, groups receiving diets of a higher caloric content showed faster $\mathrm{RMR}_{\mathrm{m} / \mathrm{p}}$-ratio recovery. Different shapes represent the $\mathrm{RMR}_{\mathrm{m} / \mathrm{p}}$-ratio values calculated using different equations; circles - Bosy-Westphal et al. [14], squares - Camps et al. [16] and rectangles - Doucet et al. [15]. 
Table 2. Paired samples t-tests for the RMR-ratio, calculated with three RMR prediction equations, and body composition for week 12 of the semi-starvation period and week 12 of the recovery period

\begin{tabular}{|c|c|c|c|c|c|c|c|}
\hline \multirow{3}{*}{$\begin{array}{l}\text { All subjects }(\mathrm{n}=32) \\
\text { RMR-ratio calculated with } \\
\text { equation based on }\end{array}$} & \multicolumn{2}{|c|}{$\begin{array}{c}\text { Starvation } \\
\text { week } 12\end{array}$} & \multicolumn{2}{|c|}{$\begin{array}{l}\text { Recovery } \\
\text { week } 12\end{array}$} & \multirow[b]{2}{*}{$t$} & \multirow[b]{2}{*}{$d f$} & \multirow[b]{2}{*}{$p$ value } \\
\hline & $M$ & $S D$ & $M$ & $S D$ & & & \\
\hline & & & & & & & \\
\hline Bosy-Westphal et al. [14] & 0.86 & 0.07 & 0.98 & 0.07 & 8.56 & 31 & $<.001$ \\
\hline Camps et al. [16] & 0.72 & 0.07 & 0.85 & 0.08 & 9.40 & 31 & $<.001$ \\
\hline Doucet et al. [15] & 0.77 & 0.07 & 0.90 & 0.08 & 9.12 & 31 & $<.001$ \\
\hline Low-calorie group $(n=8)$ & $M$ & $S D$ & $M$ & $S D$ & $t$ & $d f$ & $p$ value \\
\hline FM (kg) & 4.84 & 3.63 & 5.05 & 3.09 & 0.31 & 7 & .76 \\
\hline FFM (kg) & 52.1 & 4.24 & 50.4 & 4.32 & 2.49 & 7 & .04 \\
\hline $\begin{array}{l}\operatorname{RMR}(\mathrm{MJ} / \mathrm{d}) \\
\operatorname{RMR}(\mathrm{kcal} / \mathrm{d})\end{array}$ & $\begin{array}{l}4464 \\
1067\end{array}$ & $\begin{array}{l}378 \\
90.3\end{array}$ & $\begin{array}{l}4841 \\
1157\end{array}$ & $\begin{array}{l}250 \\
59.8\end{array}$ & 2.08 & 7 & .08 \\
\hline \multicolumn{8}{|l|}{$\begin{array}{l}\text { RMR-ratio calculated with } \\
\text { equation based on }\end{array}$} \\
\hline Bosy-Westphal et al. [14] & 0.84 & 0.07 & 0.92 & 0.07 & 3.37 & 7 & .01 \\
\hline Camps et al. [16] & 0.71 & 0.08 & 0.80 & 0.07 & 3.28 & 7 & .01 \\
\hline Doucet et al. [15] & 0.76 & 0.08 & 0.84 & 0.07 & 3.04 & 7 & .02 \\
\hline
\end{tabular}

$M$ - mean; $S D$ - standard deviation; $t$ - paired t-test statistics; $d f$ - degrees of freedom.

The results of other studies from the literature search are in line with the above data. Grande and coworkers subjected 25 young, normal weight men to a three week long caloric restriction phase $(4.18 \mathrm{MJ} / \mathrm{d}$ (1000 kcal/d)) followed by a 20 day period of overfeeding $(\geq 22.2 \mathrm{MJ} / \mathrm{d}(5300$ $\mathrm{kcal} / \mathrm{d})$ ) [20]. The subjects experienced significant weight loss and a decrease in RMR. Eight days after transitioning to an energy surplus diet, the subjects` RMR returned to baseline, even though their body weight was still $3.2 \mathrm{~kg}$ below baseline.

Müller et al. [21] performed a sequential weight change experiment 
consisting of a seven day long overfeeding period, a 21 day long energy restriction period and a subsequent 14 day long refeeding period. Bodyweight, RMR and $\mathrm{RMR}_{\mathrm{m} / \mathrm{p}}$-ratio increased as a result of overfeeding $\quad(50 \%$ above energy requirements) and decreased when the subjects underwent severe CR (50\% below energy requirements). At the end of the final refeeding period, when the subjects were still in an energy surplus, the $\mathrm{RMR}_{\mathrm{m} / \mathrm{p}}$-ratio was above the baseline value (1.22 vs. 1.20), despite identical body composition compared to baseline.

Similar results were obtained from five individuals who spent two years in a biosphere with a restricted energy intake [13]. One week after the biosphere exit, total sleeping energy expenditure (SEE) was significantly lower compared to control subjects. However, after reverting to a body composition similar to that of the control subjects, the difference was no longer present.

\subsection{Metabolic damage in} malnourished individuals

An extreme case of long-term energy restriction occurs in chronically undernourished individuals, such as patients with anorexia nervosa or malnourished populations with a poor socioeconomic status. The RMR of these individuals, when expressed in absolute terms, is lower compared to wellnourished, healthy individuals [22-26]. However, accounting for body composition offsets the relative RMR difference (Table 3). The weighted average of the $\mathrm{RMR}_{\mathrm{m} / \mathrm{p}}$-ratio, calculated with both the equation from BosyWestphal and coworkers [14] and Doucet and coworkers [15], showed that the RMR of malnourished individuals corresponds to their body composition, whereas a slightly lower $R M R_{m / p}$-ratio was found using the equation from Camps and coworkers [16]. The total RMR increases in some cases even exceeded the predicted values when malnourished individuals regained weight [27-29]. Additionally, the absolute RMR value of weight recovered patients with anorexia nervosa does not 
Medical Research Archives, Vol. 4, Issue 8, December 2016

Metabolic Damage: Do Negative Metabolic Adaptations During Underfeeding Persist After Refeeding in Non-Obese Populations?

differ from weight-matched individuals

with no history of eating disorders [24,

30]. As such, metabolic damage does not appear to reliably occur in malnourished populations.

Table 3. The ratio of measured to predicted $R M R(R M R m / p$-ratio $)$ calculated with three different RMR prediction equations

\begin{tabular}{|c|c|c|c|}
\hline $\begin{array}{l}\text { Bosy-Westphal } \\
\text { et al. [14] }\end{array}$ & Camps et al. [16] & Doucet et al. [15] & Subjects, sample size \\
\hline 1.01 & 1.04 & 1.09 & $\begin{array}{c}\text { Anorectic women, } 6 \\
{[24]}\end{array}$ \\
\hline 1.00 & 0.91 & 0.95 & $\begin{array}{l}\text { Anorectic women, } 87 \\
\text { [28] }\end{array}$ \\
\hline 0.70 & 0.73 & 0.76 & $\begin{array}{l}\text { Anorectic women, } 10 \\
\text { [29] }\end{array}$ \\
\hline 0.95 & 0.99 & 1.04 & $\begin{array}{l}\text { Anorectic women, } 12 \\
\text { [23] }\end{array}$ \\
\hline 0.79 & 0.83 & 0.87 & $\begin{array}{l}\text { Anorectic women, } 25 \\
\text { [25] }\end{array}$ \\
\hline 1.30 & 1.13 & 1.14 & $\begin{array}{c}\text { Severely undernourished men, } 30 \\
\text { [22] }\end{array}$ \\
\hline 1.03 & 1.12 & 1.16 & $\begin{array}{c}\text { Severely undernourished women, } 25 \\
\text { [22] }\end{array}$ \\
\hline \multicolumn{4}{|c|}{ Weighted average $\mathrm{RMR}_{\mathrm{m} / \mathrm{p}}$-ratio } \\
\hline 1.00 & 0.96 & 1.00 & \\
\hline
\end{tabular}




\subsection{Metabolic damage in} competitive athletes

More data contradicting dietinduced metabolic suppression comes from two case studies of natural bodybuilders undergoing contest preparation [31, 32]. These athletic, young males consumed a calorie-restricted diet for up to six months to achieve body fat levels of $4.5 \%$ and $7.5 \%$. In both cases, total RMR decreased along with weight loss. In the study conducted by Robinson and coworkers [32], the actual RMR exceeded the predicted values during the course of the entire study with a constant $\mathrm{RMR}_{\mathrm{m} / \mathrm{p}}$-ratio of $1.19-1.20$, suggesting that the athlete did not experience negative metabolic adaptations in the state of caloric restriction beyond what is expected from his changes in body composition.
In contrast, another athlete [31] experienced an $\mathrm{RMR}_{\mathrm{m} / \mathrm{p}}$-ratio decrease in the weight loss phase. However, postcontest weight regain increased his $\mathrm{RMR}_{\mathrm{m} / \mathrm{p}}$-ratio. In fact, the ratio was identical 13 weeks before and after the competition (0.87) with a value in between baseline (1.28) and after 26 weeks caloric restriction (0.74). Figure 2 depicts the body composition and metabolic changes over time of both athletes.

The same scenario was observed in 12 competitive wrestlers in a seven-month weight cycling period [33]. These athletes lost on average $4.8 \mathrm{~kg}$ during the competition season and regained $6.8 \mathrm{~kg}$ in five to six weeks after the last competition. While in an energy deficit, their average $\mathrm{RMR}_{\mathrm{m} / \mathrm{p}}$-ratio decreased from 1.29 to 1.12 ; however, it increased to 1.31 upon weight regain. 
Medical Research Archives, Vol. 4, Issue 8, December 2016

Metabolic Damage: Do Negative Metabolic Adaptations During Underfeeding Persist After Refeeding in Non-Obese Populations?
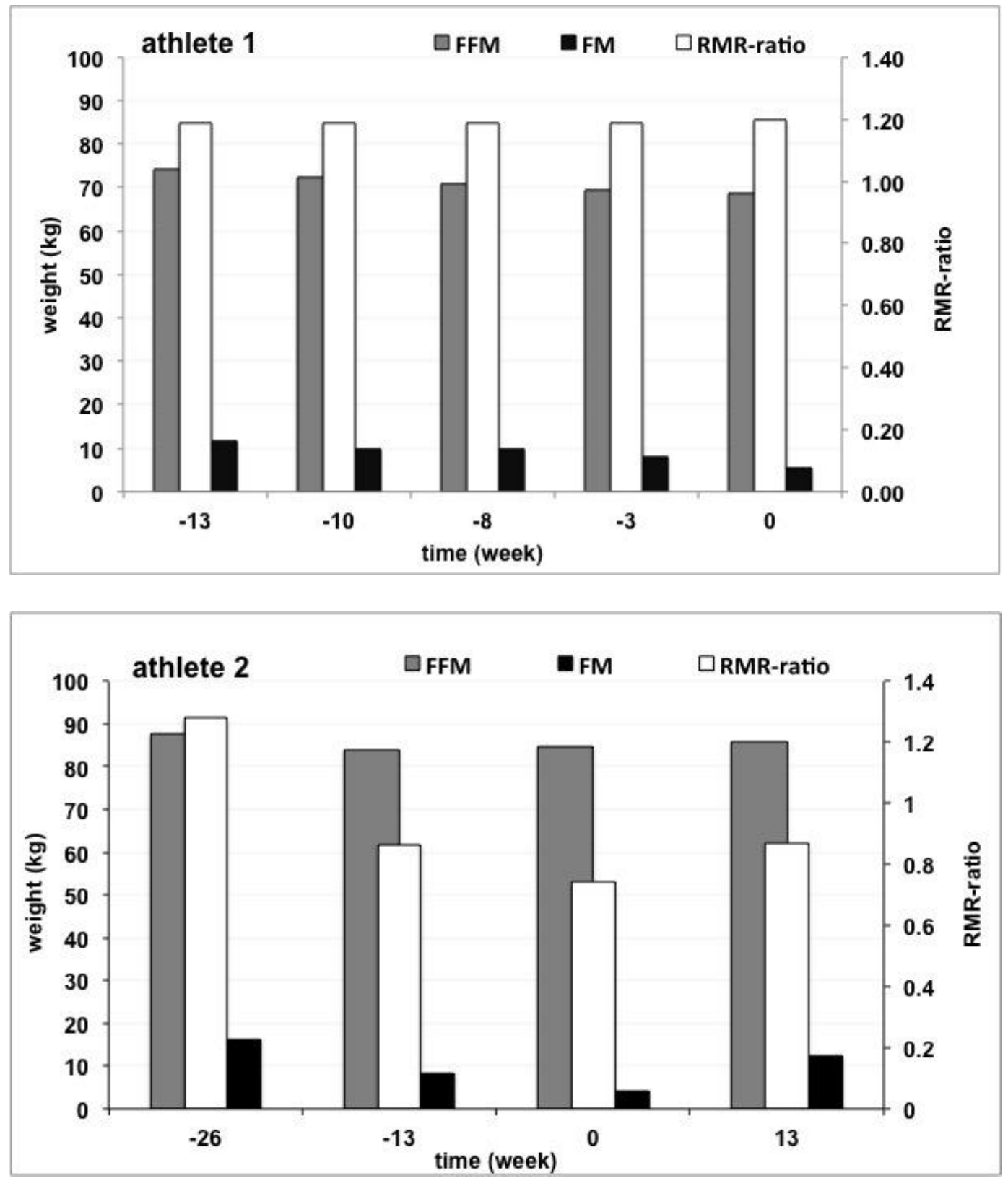

Figure 2. Changes in FFM (gray), FM (black) and $\mathrm{RMR}_{\mathrm{m} / \mathrm{p}}$-ratio (white) during weight loss (athlete 1 and 2) and weight regain (athlete 2). Week 0 indicates the end of caloric restriction for both athletes.

\section{Discussion}

Our findings contradict the hypothesis that basal metabolism permanently slows down to favor fat gain or is permanently damaged by undergoing a prolonged period of caloric restriction $[1,7]$. 
The discrepancy between our findings and previous reports has several potential reasons. Previous studies revising the Minnesota experiment did not analyze the complete recovery period and disregarded the varying recovery conditions, i.e. energy balance, among the subjects. The 12-week post-starvation recovery period analyzed by Dulloo and coworkers [7, 34] was not sufficient for full metabolic recovery: full restoration of the $R M R_{m / p}$-ratio occurred after 20 weeks of refeeding. The lack of complete recovery within 12 weeks was not surprising, considering that in the first half of the 12-week controlled recovery period the subjects received diets containing fewer calories than initially planned and one half of the subjects rehabilitated only to a small degree. Notably, Dulloo and coworkers [7] did not take into account that the subjects were divided into 4 groups that received diets of a different caloric content during the 12 weeks of controlled rehabilitation. The groups receiving diets of a higher caloric content, consuming up to $4.2 \mathrm{MJ} / \mathrm{d}(1014 \mathrm{kcal} / \mathrm{d})$ more than the low calorie group, experienced faster body weight and RMR recovery than the low calorie group. Not taking into account this significant difference in energy intake may be the reason why the researchers $[7,34]$ concluded that RMR recovers in relation to the degree of FM recovery without being influenced by the recovery of the more metabolically active FFM. The findings here provide evidence that faster RMR recovery and higher FM replenishment resulted from a higher caloric intake (Figure 1), contradicting the idea that faster RMR recovery is primarily a function of fat store replenishment.

The results here challenge the hypothesis of a "metabolic memory," which states that thermogenesis is suppressed until fat stores revert to their initial size ("fat-stores memory") [7]. The findings here suggest that the suppression of basal metabolism, which is a component of thermogenesis [35], is a function of caloric intake and changes in body composition. Even though the subjects in the low-calorie group did not experience full metabolic recovery due to their low energy intake, their $\mathrm{RMR}_{\mathrm{m} / \mathrm{p}^{-}}$ 
ratio was still significantly higher in the recovery period than in the semistarvation period, despite a less favorable body composition (Table 2). In contrast, positive energy balance following CR readily undoes short-term AT and restores thyroid hormone levels and SNS activity [21, 28]. Thus, RMR measurements taken in a calorie-restricted state, without considering the influence of energy balance on RMR, may potentially yield misleading results in favor of the metabolic damage hypothesis.

Another reason for the finding of purported metabolic damage in previous studies is that RMR predictions in favor of the 'metabolic slowing' hypothesis that showed a decrease in RMR originated from weight loss studies on obese individuals. These studies appear to have overestimated the actual RMR [1] of postobese individuals due to the fact that their predictions were based on FM and FFM changes without accounting for changes in FFM relative to organ mass, as described earlier $[17,36]$.

It is important to note that AT was frequently observed in well-nourished individuals subjected to a period of acute energy restriction [37], even though here the RMR of chronically undernourished individuals corresponded to their body composition (Table 3), suggesting that AT was absent during chronic CR [37].

A limitation of this review is that the data on individual subjects is lacking for the majority of research studies. As such, data on body composition and metabolic parameters were only suitable for statistical analysis in the Minnesota experiment. Additionally, pre-anorexic data on RMR from anorexia nervosa patients are absent, making before and after RMR comparisons impossible. Another limitation of the current research is that some research studies were limited either by their length, consisting of a total three week diet- and refeeding period, or contrasted by single-case studies done on bodybuilders that are limited in their sample size. Future research may further our understanding of human metabolic changes by investigating multiple weight cycling phases in various populations with sufficient sample sizes to achieve satisfactory statistical power. 
Medical Research Archives, Vol. 4, Issue 8, December 2016

Metabolic Damage: Do Negative Metabolic Adaptations During Underfeeding Persist After Refeeding in Non-Obese Populations?

\section{Conclusion}

Body composition is the most influential determinant of RMR in neutral energy balance. Short-term changes in energy balance induce metabolic adaptations that change RMR correspondingly. During long-term caloric restriction, AT occurs and RMR often decreases relative to FM and FFM loss [37]. Positive energy balance undoes the negative metabolic effects of AT and causes RMR to return to a level that is appropriate for the body composition at that time. The findings here show that human metabolism is highly plastic and rapidly adapts to changes in energy availability and body composition. This stands in contrast to the hypothesis of an inflexible metabolism that is susceptible to metabolic damage during prolonged caloric restriction. As such, the presence of metabolic damage in non-obese individuals is not supported by the current literature.

Financial support: none 
Medical Research Archives, Vol. 4, Issue 8, December 2016

Metabolic Damage: Do Negative Metabolic Adaptations During Underfeeding Persist After Refeeding in Non-Obese Populations?

\section{References}

1. Johannsen DL, Knuth ND, Huizenga

$\mathrm{R}$ et al. Metabolic Slowing with

Massive Weight Loss despite

Preservation of Fat-Free Mass. J. Clin.

Endocrinol. Metab. 2012; 97(7):2489-

2496. [PubMed: 22535969]

2. Rosenbaum M, Hirsch J, Gallagher DA, Leibel RL. Long-term persistence of adaptive thermogenesis in subjects who have maintained a reduced body weight. Am. J. Clin. Nutr. 2008; 88(4):906-912. [PubMed: 18842775]

3. Astrup A, Gøtzsche PC, van de Werken $\mathrm{K}$ et al. Meta-analysis of resting metabolic rate in formerly obese subjects. Am. J. Clin. Nutr. 1999; 69:1117-1122. [PubMed: 10357728]

4. Fothergill E, Guo J, Howard L et al. Persistent metabolic adaptation 6 years after "The Biggest Loser" competition. Obesity 2016; 24(8):1612-1619. [PubMed: 27136388]

5. Keys A, Brozek J, Henschel A et al
The Biology of Human Starvation, University of Minnesota Press, Minneapolis, MN., 1950.

6. Dulloo AG, Jacquet J. Adaptive reduction in basal metabolic rate in response to food deprivation in humans: A role for feedback signals from fat stores. Am. J. Clin. Nutr. 1998; 68:599-606. [PubMed: 9734736]

7. Dulloo AG, Jacquet J, Girardier L. Autoregulation of body composition during weight recovery in human: the Minnesota Experiment revisited. Int. J. Obes. 1996; 20:393-405. [PubMed: 8696417]

8. Dulloo AG, Jacquet J, Montani J-P. How dieting makes the lean fatter: from a perspective of body composition autoregulation through adipostats and proteinstats awaiting discovery. Obes. Rev. 2015; 16(Suppl 1):25-35. [PubMed: 25614201]

9. Saarni SE, Rissanen A, Sarna S et al. 
Weight cycling of athletes and subsequent weight gain in middleage. Int. J. Obes. 2006; 30(11):1639-44. [PubMed: 16568134]

10. Dulloo AG, Jacquet J, Seydoux J, Montani J-P. The thrifty "catch-up fat" phenotype: its impact on insulin sensitivity during growth trajectories to obesity and metabolic syndrome. Int. J. Obes. 2006; 30:S23-S35. [PubMed: 17133232]

11. Diedrichs PC, Lee C, Kelly M. Seeing the beauty in everyday people: a qualitative study of young Australians' opinions on body image, the mass media and models. Body Image 2011; 8(3):259-66. [PubMed: 21561819]

12. Kenardy J, Brown WJ, Vogt E. Dieting and Health in Young Australian Women. Eur. Eat. Disord. Rev. 2001; 4(9):242-254. Retrieved from

http://onlinelibrary.wiley.com/doi/10.1 002/erv.388/epdf

13. Weyer C, Walford RL, Harper IT et al.
Energy metabolism after 2 y of energy restriction: The Biosphere 2 experiment. Am. J. Clin. Nutr. 2000; 72:946-953. [PubMed: 11010936]

14. Bosy-Westphal A, Müller MJ, Boschmann $\mathrm{M}$ et al. Grade of adiposity affects the impact of fat mass on resting energy expenditure in women. Br. J. Nutr. 2009; 101(4):474-7. [PubMed: 19230079]

15. Doucet E, St-Pierre S, Almeras $\mathrm{N}$ et al. Evidence for the existence of adaptive thermogenesis during weight loss. Br J Nutr 2001; 85(6):715-723. [PubMed: 11430776]

16. Camps SGJA, Verhoef SPM, Westerterp KR. Weight loss, weight maintenance, and adaptive thermogenesis. Am. J. Clin. Nutr. 2013; 97(5):990-4. [PubMed: 23535105]

17. Bosy-Westphal A, Braun W, Schautz B, Müller MJ. Issues in characterizing resting energy expenditure in obesity and after weight loss. Front. Physiol. 
Medical Research Archives, Vol. 4, Issue 8, December 2016

Metabolic Damage: Do Negative Metabolic Adaptations During Underfeeding Persist After Refeeding in Non-Obese Populations?

2013; 4(March):47. [PubMed:

102:807-819. [PubMed: 26399868]

23532370]

18. Johnstone AM, Murison SD, Duncan JS et al. Factors influencing variation in basal metabolic rate include fat-free mass, fat mass, age, and circulating thyroxine but not sex, circulating leptin, or triiodothyronine. Am. J.

Clin. Nutr. 2005; 82:941-948. [PubMed: 16280423]

19. Hall KD. Computational model of in vivo human energy metabolism during semistarvation and refeeding. Am. J. Physiol. Endocrinol. Metab. 2006; 291:E23-E37. [PubMed: 16449298]

20. Grande F, Anderson JT, Keys A. Changes of Basal Metabolic Rate in Man in Semistarvation und Refeeding. J. Appl. Physiol. 1958; 12:230-238. [PubMed: 13525268]

21. Müller MJ, Enderle J, Pourhassan M et al. Metabolic adaptation to caloric restrication and subsequent refeeding: the Minnesota Starvation Experiment revisited. Am. J. Clin. Nutr. 2015; 
Medical Research Archives, Vol. 4, Issue 8, December 2016

Metabolic Damage: Do Negative Metabolic Adaptations During Underfeeding

Persist After Refeeding in Non-Obese Populations?

Metab. 2014; 99(3):908-914.

[PubMed: 24302748]

26. Haas V, Onur S, Paul T et al. Leptin and body weight regulation in patients with anorexia nervosa before and during weight recovery. Am. J. Clin. Nutr. 2005; 81(4):889-896. [PubMed: $15817868]$

27. Russell J, Baur L, Beumont P et al. Refeeding of anorexics : wasteful not wilful. Lancet 1998; 352:1445-1446. [PubMed: 9808001]

28. Wymelbeke V Van, Brondel L, Brun JM, Rigaud D. Factors associated with the increase in resting energy expenditure during refeeding in malnourished anorexia nervosa patients. Am. J. Clin. Nutr. 2004; 80:1469-1477. [PubMed: 15585757]

29. Obarzanek E, Lesem MD, Jimerson DC. Resting metabolic rate of anorexia nervosa patients during weight gain. Am.J.Clin.Nutr. 1994; 60(5):666-675. [PubMed: 7942571]

30. Dellava JE, Policastro P, Hoffman DJ.
Energy metabolism and body composition in long-term recovery from anorexia nervosa. Int. J. Eat. Disord. 2009; 42(5):415-21. [PubMed: 19107831]

31. Rossow LM, Fukuda DH, Fahs CA et al. Natural bodybuilding competition preparation and recovery: A 12-month case study. Int. J. Sports Physiol. Perform. 2013; 8(5):582-592. [PubMed: 23412685]

32. Robinson SL, Lambeth-Mansell A, Gillibrand $\mathrm{G}$ et al. A nutrition and conditioning intervention for natural bodybuilding contest preparation: case study. J. Int. Soc. Sports Nutr. 2015; 12:1-11. [PubMed: 25949233]

33. Melby CL, Schmidt WD, Corrigan D. Resting metabolic rate in weightcycling collegiate wrestlers compared with physically active, noncycling control subjects. Am. J. Clin. Nutr. 1990; 52(3):409-414. [PubMed: 2393002]

34. Dulloo AG, Jacquet J, Girardier L. 
Medical Research Archives, Vol. 4, Issue 8, December 2016

Metabolic Damage: Do Negative Metabolic Adaptations During Underfeeding Persist After Refeeding in Non-Obese Populations?

Poststarvation hyperphagia and body fat overshooting in humans: A role for feedback signals from lean and fat tissues. Am. J. Clin. Nutr. 1997; 65(3):717-723. [PubMed: 9062520]

35. Müller MJ, Bosy-Westphal A. 37. Shetty PS. Adaptation to low energy Adaptive thermogenesis with weight loss in humans. Obesity 2013; 21(2):218-228. [PubMed: 23404923]

36. Bosy-Westphal A, Kahlhöfer J, Lagerpusch $\mathrm{M}$ et al. Deep body composition phenotyping during weight cycling: relevance to metabolic efficiency and metabolic risk. Obes Rev 2015; 16(February):36-44. [PubMed: 25614202] intakes: the responses and limits to low intakes in infants, children and adults. Eur. J. Clin. Nutr. 1999; 53:S14-S33. [PubMed: 10365978] 